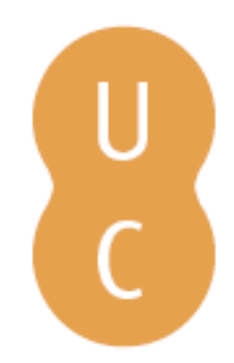

\title{
nommalina
}

\section{Visão e interpretação senequiana do mito de Fedra e Hipólito: a personagem feminina de Fedra}
Autor(es):
Arias Abellán, C.
Publicado por: Centro de Estudos Clássicos e Humanísticos da Universidade de URL persistente: Coimbra; Imprensa da Universidade de Coimbra
DOI: DOI:http://dx.doi.org/10.14195/978-989-721-010-5_5
Accessed : $\quad$ 26-Apr-2023 07:05:56

A navegação consulta e descarregamento dos títulos inseridos nas Bibliotecas Digitais UC Digitalis, UC Pombalina e UC Impactum, pressupõem a aceitação plena e sem reservas dos Termos e Condições de Uso destas Bibliotecas Digitais, disponíveis em https://digitalis.uc.pt/pt-pt/termos.

Conforme exposto nos referidos Termos e Condições de Uso, o descarregamento de títulos de acesso restrito requer uma licença válida de autorização devendo o utilizador aceder ao(s) documento(s) a partir de um endereço de IP da instituição detentora da supramencionada licença.

Ao utilizador é apenas permitido o descarregamento para uso pessoal, pelo que o emprego do(s) título(s) descarregado(s) para outro fim, designadamente comercial, carece de autorização do respetivo autor ou editor da obra.

Na medida em que todas as obras da UC Digitalis se encontram protegidas pelo Código do Direito de Autor e Direitos Conexos e demais legislação aplicável, toda a cópia, parcial ou total, deste documento, nos casos em que é legalmente admitida, deverá conter ou fazer-se acompanhar por este aviso.

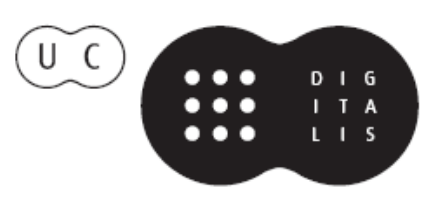




\section{Hipólito e Fedra}

\section{nos caminhos de um mito}

Carlos A. Martins de Jesus, Claudio Castro Filho, José Ribeiro Ferreira (coords.) 


\title{
VisÃo e interpretação SENEQUiANa do Mito de Fedra e Hipólito: A PERSONAGEM FEMININA DE FEDRA
}

\author{
C. Arias Abellán \\ Universidade de Sevilha
}

\section{Introdução}

O presente trabalho integra-se no âmbito de um projeto de investigação ${ }^{1}$ destinado à caracterização dos personagens (e dos temas) das tragédias de Séneca a partir da análise do vocabulário ou, dito de outra forma, ao exame do traço dramático ao nível da palavra.

$\mathrm{Na}$ minha opinião, e em especial em áreas como a da tragédia, é o discurso das personagens, o que empregam sobre si próprias ou o que se refere a uma personagem em concreto, pela boca de outra personagem, o que pode traçar - de forma mais contundente e "refinada" que a simples análise literária - o retrato da sua singularidade enquanto personagens trágicas, as suas tomadas de posição face ao núcleo trágico e aos demais atores. E mantenho esta opinião quanto à real capacidade caracterizadora do léxico a respeito das "problemáticas" explanadas na tragédia. Mais, ela é ainda fundamental para o conhecimento das conceções particulares dos autores trágicos sobre as personagens e os temas básicos da tragédia, e, por último, da posição característica destes autores e da sua originalidade em relação às fontes.

O mito de Hipólito e Fedra, representado em cinco antecedentes literários anteriores a Séneca - o Hipólito Velado e o Hipólito portador da Coroa de Eurípides, a Fedra de Sófocles, a peça homónima de Lícofron e a quarta Heroide de $\mathrm{Ovídio}^{2}$-, remonta com efeito a uma velha lenda ritual relacionada com o culto a Poséidon e à morte de Hipólito, jovem herói, belo e virgem; com esta história parece ter-se depois misturado a figura lendária de Teseu e, sobretudo, ter sido introduzida, como figura oponente à de Hipólito, a personagem de Fedra, uma mulher impudica (cf. J. Luque Moreno II 1980: 17 sqq.).

Uma das linhas evolutivas deste mito reside precisamente no progressivo protagonismo de Fedra (e consequente afastamento de Hipólito), junto com a igualmente progressiva reabilitação moral do seu comportamento, assunto a que voltaremos adiante.

\footnotetext{
${ }^{1}$ A primeira publicação deste projeto data de 1994.

2 De entre estes antecedentes, perderam-se Hipólito Velado de Eurípides e as Fedras de Sófocles e Lícofron. Cf., a propósito, L. Luque Moreno II 1980: 16-17 e, neste volume, as pp. 25, 116-117 e 196 e n. 9.
} 
Baseando-me na história literária que acabo de resumir, centrarei este estudo na personagem que, na referida história, foi adquirindo importância, Fedra $^{3}$ (que é, antes de mais, a protagonista da obra de Séneca), e no seu tema fundamental, motor de toda a tragédia: o seu amor. Bem assim, limitarei a minha análise à categoria lexical dos adjetivos, porquanto me parece que este tipo de vocabulário é o que mais nos convém para uma aproximação ao desenho dos atores e dos temas trágicos, tratando-se do nível em que repousa a maioria das nuances semânticas de índole valorativa.

\section{A personagem de Fedra}

Os adjetivos que incidem diretamente sobre Fedra podem agrupar-se em três domínios fundamentais: signa amoris, atitudes de Fedra perante Hipólito e valoração moral da conduta de Fedra.

\section{Signa amoris}

O primeiro grupo dos signa amoris constitui-se por um conjunto de qualificativos que conotam os afetos provocados pelo amor; estes descrevem-se por via de uma série de procedimentos que cabem nos motivos amorosos tradicionais (angústia, perda de controle, abatimento, etc.), levados às últimas consequências nesta obra, pois que nela está em causa um amor, o de Fedra, sem solução, cuja concretização implicaria uma relação incestuosa e adúltera que, como tal, seria contrária à pietas.

Destes pressupostos parece partir Fedra quando, como veremos adiante, tenta justificar o despropósito dos seus sentimentos apelando ao estado de "loucura" ao qual a conduziram esses mesmos sentimentos e ao seu caráter inevitável e "fatal". Podem estes signa amoris ser de índole psíquica e física, surgindo concretizados com adjetivos dos seguintes âmbitos semânticos: (1) “Tristeza" e "tribulação"; (2) "Incerteza", "desassossego"; (3) "Irracionalidade”, "loucura"; (4) manifestação física destes sintomas ("enfraquecimento" e "desvanecimento").

1. A "tristeza" e a "tribulação" estão representadas pelo termo miser, com o qual Fedra é qualificada pela Ama - Quis meas miserae deus/ aut quis iunare Daedalus flammas queat? (vv. 119-20); Quo, misera, pergis (v. 142) - e por maestus, adjetivo que Fedra aplica a si mesma - Hanc maestam prius recreate (v. 730$)^{4}$.

${ }^{3}$ Sobre esta personagem elaborámos já alguma reflexão prévia. Cf. C. Arias Abellán 1994: 33-35. Este estudo, limitando-se a uma análise interna da obra, serve logicamente de antecedente ao presente trabalho, onde se incluem já, além de outras considerações, a indagação e a comparação com as fontes gregas e latinas da obra.

${ }^{4}$ Outros planos gramaticais abundam a propósito deste estado de "tristeza". São disso exemplo os passos da Ama como noctem querelis ducit (v. 370), lacrimae cadunt per ora et assiduo genael rore irrigantur, qualiter Tauri iugis/ tepido madescunt imbre percussae niues (vv. 381-383); ou as 
2. O "desassossego" e a "incerteza" da rainha surgem nomeados, por sua vez, pelos adjetivos dubius (v. 365), incertus (v. 366) e impatiens (v. 372) do discurso seguinte da Ama:

quamuis tegatur, proditur uultu furor; (...) nil idem dubiae placet

artusque uarie iactat incertus dolor.

Nunc ut soluto labitur moriens gradu

et uix labante sustinet collo caput,

nunc se quieti redditet, somni immemor, noctem querelis ducit; attolli iubet

iterumque poni corpus et solui comas rursus fingi; semper impatiens sui

mutatur habitus (vv. 363, 365-373) ${ }^{5}$.

3. A zona da "precipitação" e da "irracionalidade" de Fedra cobra uma importância muito especial e apresenta-se com um número bastante maior de qualificativos que correspondem, na sua maioria, a qualificações pela boca da própria rainha. São eles os seguintes: praeceps (Sed Phaedra praeceps graditur, impatiens morae. Quo se dedit fortuna? Quo uerget furor?, vv. 583-84); o particípio presente do verbo furo (quid furens saltus amas?, v. 112; Hyppoyte nunc me compotem uoti facis; / sanas furentem. maius hoc uoto meo est,/ saluo ut pudore manibus immoriar suis, v. 711); o deverbativo furibundus (siste furibundum impetum, v. 263); dois compostos privativos de mens, amens e demens (et te per undas perque Tartareos lacus/ per Styga, per amnes igneos amens sequar, vv. 1179-1180; Athenae, tuque, funesta pater/ peior nouerca: falsa memoraui et nefas,/ quod ipse demens pectore insano hauseram, / mentite finxi. Vana punisti pater, vv. 1191-94); um composto privativo de cors, uecors (strictoque vaecors Phaedra quid ferro parat?, v. 1155); sintagmas formados por mens, pectus e adjetivos alusivos às noções de falta de sanidade ou freio como effrena mens (Moderare, alumna, mentis effrenael animos coerce, $\mathrm{v}$. 255), non sana mens (Sed en, patescunt regiae fastigia: reclinis ipsa sedis auratae torol solitos amictos mente non sana abnuit, vv. 384-386), insanum pectus (pectus insanum uapor ardorque torret, vv. 640-641); e, finalmente, perífrases referentes à falta de domínio sobre o seu ser (et ipsa nostrae fata cognosco domus:/ fugienda petimus; sed mei non sum potens, vv. 698-699).

Não restam dúvidas de que a sua "loucura" tem especial significado para Fedra e que é isso que determina o predomínio, nas suas palavras, de qualificativos alusivos a este estado ${ }^{6}$. Por outro lado, estas situações de

seguintes palavras de Teseu, quando regressa dos Infernos e escuta os lamentos da esposa: fremitus flebilis (v. 850); maesta lamentatio (v. 852).

${ }^{5}$ Este estado de "desassossego" e "incerteza" é reforçado com outros elementos lexicais do contexto (cf. incertus dolor; uarie; nunc... nunc... iterum... rursus... mutatur).

${ }^{6}$ Das dez referências à "loucura", metade (cinco) pertencem a Fedra, repartindo-se as restantes pelo Coro (uma) e pela Ama (quatro). 
“infortúnio" e "loucura" projetam-se na "insónia" (outro tópico amoroso) da rainha, assinalado pela Ama (somni immemor, v. 369).

4. Motivo de pormenorizada descrição são as mostras físicas do estado de Fedra: desatenção para com a comida e a saúde - integrada no tópico do esquecimento das necessidades primárias característico do amor -, perda da beleza, enfraquecimento físico, etc. Todas estas manifestações, consequência do estado de incerteza e excitação amorosas da rainha, podemos lê-las nos passos seguintes: nulla iam Cereris subit cura aut salutis (vv. 373-374); cecidit decor (v. 378); oculi nibil... micant (v. 380); non idem uigor (v. 375); iam uiribus defecta (v. 375). Bem assim, apontam para a situação inanimada e moribunda da rainha: nunc ut soluto labitur moriens gradu (v. 367); terrae repente corpus exanimum accidit/ et ora morti similis obduxit color (vv. 585-86).

Com todas estas descrições, Séneca parece colocar a tónica do sofrimento amoroso de Fedra na ideia de uma autêntica doença, algo que não é estranho ao Hipólito euripidiano, como demonstra neste volume o estudo de Frederico Lourenço (pp. 31-36)

\section{Atitudes de Fedra perante Hipólito}

No que toca às atitudes de Fedra perante Hipólito, destaca-se a de suplicante. Esta postura em face do amado integra-se no motivo amatório do seruitium amoris (omne seruitium feram, v. 612) e tem a sua representação adjetiva (além do substantivo famula, nos versos 611, 612 e 617) nos termos supplex e serua, com os quais Fedra se autoqualifica diante de Hipólito (sinu receptam supplicem ac seruam tege, v. 622), a par da sua posição de "cumpridora obediente" do poder que, segundo ela, poderia estar nas mãos do seu enteado ${ }^{7}$ (mandata recipe sceptra, me famulam accipel, te imperia regere, me decet iussa exequi, vv. 617-18; iubeas, v. 613; imperium, v. 621; etc. $)^{8}$.

\section{Valoração "moral" da conduta de Fedra}

Articula-se em torno de três conceitos: (1) "castidade", (2) pietas e (3) "culpabilidade (inocência)".

1. Prevalece, a este respeito, o convencimento da "castidade" da rainha, sustentado pelos qualificativos pudica, casta e o poético castifica, que lhe atribui

${ }^{7}$ Fedra baseia-se no facto de Teseu estar nos Infernos e na esperança de que possa morrer aí e não mais regressar, esperança que a ilibaria dos delitos de adultério (e de incesto) e que facilitaria a possibilidade de Hipólito ocupar o lugar de Teseu, como rei e como esposo. Esta localização de Teseu nos Infernos, que viria a "anular" ou a "diminuir" os pecados de Fedra, pode dever-se, segundo P. Grimal 1965: 4, a Sófocles.

${ }^{8}$ É neste contexto das reações perante Hipólito que se situa, ainda que com uma única representação adjetiva, o estado de "inatividade" de Fedra, que a Ama denomina com o termo segnis, causada, bem como a "indolência" de Fedra (outro tópico da poesia amatória) pelo aturdimento a que se vê submetida a rainha após a confissão a Hipólito dos seus sentimentos e a recusa destes pelo enteado: Deprensa culpa est. Anime, quid segnis stupes? (v. 719). 
a Ama: pudica9 (Nefandi raptor Hippolytus stupril instat premitque, mortis intentat metum, / ferro pudicam terret, vv. 726-728); casto pectore (Thesea coniunx, clara progenies Iouis,/ nefanda casto pectore exturba ocius, vv. 129-130); castifica (expelle facinus mente castifica horridum, v. 169). E também Fedra reafirma esta castidade, referindo-se a si mesma com a palavra intacta (Respersa nulla labe et intacta, innocens/ tibi mutor uni, vv. 668-669) e por outros meios sintagmáticos, como seja a expressão saluo pudore (Maius hoc uoto meo est,/ saluo ut pudore manibus immoriar tuis, vv. 711-712). Presente está ainda a representação, por via da antinomia adjetiva castal incesta, da situação que a domina no fim da peça (morere, si casta es uiro, si incesta, amori, vv. 1184-85), já que considera que, tenha ou não sido casta, deve pagar com a morte a dor que causou ao esposo e ao amado, Hipólito.

2. A falta de pietas expressa-se com o adjetivo impius, usado em três ocasiões relativamente a Fedra e obedecendo: a uma advertência da Ama, no início da obra, a propósito dos planos da rainha em unir-se a Hipólito e às consequências desse ato, a confusão, no leito, de pai e filho, e a conceção no seu ventre ímpio (utero impio) de uma descendência híbrida (Miscere thalamos patris et gnati apparas/ uteroque prolem capere confusam impio?, vv. 171-172); a uma autoqualificação da própria Fedra, quando decide suicidar-se após reconhecer a sua culpa (pectus impium) na mentira contra Hipólito e, como tal, na morte deste (Mucrone pectus impium iusto patet, v. 1197); finalmente, a uma declaração de Teseu, no momento em que lança a maldição final contra a esposa (Istam terra defossam premat/ grauisque tellus impio capiti incubet, vv. 1279-1280).

3. À parte a aceitação, que acabo de assinalar, da sua falta contra a pietas (pectus impium), motivadora da calúnia contra Hipólito e da sua morte, não há na verdade - e com isto passo à análise do âmbito da "culpabilidade" ou "inocência” - lugar para a aceitação da culpa no que toca ao amor.

Fedra declara-se innocens quando confessa esse amor a Hipólito (Respersa nulla labe et intacta, innocens/ tibi mutor uni, vv. 668-669), pese embora o apelo que lhe faz a Ama com vista a uma possível interiorização ética da culpabilidade deste sentimento por um enteado (quid poena praesens conscius mentis pauor/ animusque culpa plenus et semet timens?, vv. 162-163).

Nos momentos em que emergem sentimentos negativos de autopunição, a rainha apela à ausência de Teseu nos Infernos - pela primeira vez referida, como vimos, por Sófocles -, servindo-se dela com um duplo fim: se por um lado a dita distância de Teseu nos Infernos - e a possibilidade aguardada por Fedra de que aí encontre a morte, de que jamais regresse - a ilibam do delito

${ }^{9}$ Hipólito, como é natural, contraria esta valoração lançando mão do antónimo impudicus para qualificar Fedra: Procul impudicos corpore a casto amouel tactus (vv. 704-705); En impudicum crine contorto caput/laeua reflexi (vv. 707-708). 
de adultério (e de incesto) e a levam, além disso, a conceber a esperança de um casamento com Hipólito, o que daria legalidade ao seu amor, por outro Teseu partiu para os Infernos em busca de amores ilícitos (illicitos toros... quaerit Hippolyti pater, vv. $97-98^{10}$ ), o que torna o esposo quem primeiro foi infiel, assim fazendo da possível infidelidade de Fedra uma simples resposta:

\author{
Profugus en coniunx abest \\ praestatque nuptae quam solet Theseus fidem \\ Fortis per altas inuii retro lacus \\ uadit tenebras miles audacis proci, \\ solio ut reuulsam regis inferni abstrahat; \\ pergit furoris socius, haud illum timor \\ pudorque tenuit: stupra et illicitos toros \\ Acheronte in imo quaerit Hyppolyti pater (vv. 91-97) ${ }^{11}$.
}

Dos qualificativos referentes a Fedra, usados pela própria ou por outras personagens da obra, concluímos alguns traços que passamos a resumir, antes de passar ao estudo do amor.

No âmbito dos signa amoris e das atitudes da mulher apaixonada, destaca-se com termos absolutos o "estado de loucura" da personagem. Pode afirmar-se que a "irracionalidade" é a sua característica fundamental, sendo os restantes sintomas ("tristeza", "desassossego", etc.) remetidos para segundo plano.

Por outro lado, ao passo que estes sintomas se deduzem sobretudo das palavras e intervenções da Ama, as situações de "descontrole" e "loucura" erguem-se da afirmação mais categórica e dorida que de si mesma faz Fedra. Assim se enfrenta a rainha à sua paixão amorosa, como que a uma vitória do furor em face da ratio, vitória essa que é causa de imensa contradição interior, de profundo tormento, dos quais dá provas em mais do que uma ocasião com afirmações como a seguinte:
sed furor cogit sequi
peiora. Vadit animus in praeceps sciens
remeatque frustra sana consilia appetens...
Quid ratio possit? Vicit ac regnat furor (vv. 178-180; 184) ${ }^{12}$

\footnotetext{
${ }^{10} \mathrm{O}$ alvo dos seus amores seria Pirítoo. Cf. J. Luque Moreno II 1980: 31, n. 51.

${ }^{11}$ Este argumento da infidelidade inicial de Teseu tem também especial relevo na quarta Heroide de Ovídio (vv. 109 sqq.).

${ }^{12} \mathrm{O}$ par ratio/ furor a que apela Fedra neste passo, par de índole psicológica e filosófica, é o pivô da tragédia. Em Fedra, como a própria manifesta e como podemos depreender de toda esta investigação, cumpre-se o triunfo do furor (situação partilhada com Teseu); em Hipólito e na Ama parece dominar, ao invés, a ratio. Para mais detalhes, vd. E. Lefevre 1969: 131-160 e J. Luque Moreno II 1980: 19.
} 
Da mesma maneira, tampouco as áreas de valoração moral da paixão e da conduta de Fedra conseguem a relevância e a especificação da sua "loucura".

É feita referência - em seis momentos, como vimos (três da Ama, três de Fedra) - ao tema da "castidade" da rainha, ao que se seguem, de longe, os dois planos da sua "inocência (culpabilidade)" e da pietas ${ }^{13}$ : Fedra verbaliza a "inocência" do seu amor por Hipólito (qualificando-se de innocens); quanto à falta de pietas, essa é uma falta que não se reconhece no amor de Fedra, mas sim na difamação lançada contra Hipólito no final da obra, causa da sua morte.

\section{O amor}

Não restam dúvidas que o tema dominante na personagem de Fedra é o amor, tema que passo a analisar com o objetivo de traçar o perfil desta personagem. $\mathrm{O}$ léxico adjetivo permite-nos distinguir referências ao amor em geral e referências particulares ao amor concreto vivido por Fedra.

\section{O amor como sentimento geral}

Conhecemos este sentimento geral sobretudo pela ode coral que encerra o Ato I, ode que se inicia com uma apóstrofe a Vénus ${ }^{14}$ e se centra na omnipresença e no poder do amor na natureza (humana, animal e divina), ao que dificilmente poderia escapar Fedra.

O coro representa o amor através de Cupido e com as suas tradicionais atribuições mitológicas: como ser alado, pelo emprego dos termos poéticos uolucer e uolans (bic uolucer omni pollet in terra patens, v. 186; ille per caelum uolans, v. 200); como menino brincalhão, lascivo e ágil no arremesso dos dardos (iste lasciuus puer et renidens, v. 277; figit sagitta certior missa puer, v. 193); e como "fogo" - comparação muito frequente na poesia amatória -, um fogo que é "sagrado" (sacer) e "cruel" (saeuus) (Sacer est ignis (credite laesis)/ nimiumque potens, vv. 330-331; Saeuis ecquis est flammis modus?, v. 358) ${ }^{15}$.

${ }^{13}$ Com duas referências, de Fedra e da Ama, e três, da Ama, de Fedra e de Teseu, respetivamente.

${ }^{14}$ Ao nível das divindades é de notar o paralelismo entre Vénus (Afrodite), que preside ao mundo de Fedra, e Diana (Ártemis), que representa Hipólito (Regina nemorum, v. 406; toruus auersus ferox/ in iura Veneris redeat, vv. 416-417).

${ }^{15}$ A par desta descrição do coro, que mantém o esquema tradicional das suas representações mitológicas e do seu poder, surge uma reflexão de natureza "valorativa" por parte de Ama e da protagonista; a Ama considera-o ficção de um animus demens (v. 197) e da turpis libido (vv. 202203), aplicando apenas numa ocasião, referente a um amor dentro dos limites da razão, o termo positivo sanctus (Cur sancta paruis habitat in tectis Venus/mediumque sanos uulgus affectus tenet/ et se corcent modica?, vv. 211-213). Já Fedra fala de uma "chama indomável" (flammis... indomitis, v. 187) ou de algo "enganador" (O spes amantum credula, o fallax Amor, v. 634). 


\section{O amor sentido por Fedra}

O amor de Fedra vem assinalado, na maioria dos contextos, com substantivos abstratos - contando com não mais que uns poucos casos de concretização por via das divindades do amor, Vénus e Cupido -, e recebe um conjunto de adjetivações que traçam dele a imagem de uma realidade intensamente interiorizada e de maior profundidade do que a que se obtém pelas referências ao amor em geral realizadas pelo coro, que acabámos de ver.

Como substantivo abstrato, conhece diversas identificações. Em primeiro lugar, é comparado ao "fogo" - no âmbito da metáfora tão característica da poesia amatória que mencionei na secção anterior. Este "fogo de amor" recebe a incidência de adjetivos como tacitus e mersus, reveladores do seu caráter "secreto" e "oculto", caráter que concorda com o tema da honra, pois que se trata, em Fedra, de um amor ilegítimo, desonroso e pouco coincidente com o comportamento de uma rainha: torretur aestu tacitu et inclusus quoque, / quamuis tegatur, proditur uultu furor (v. 362); per uenas meat/ uisceribus ignis mersus et uenus latens/ ut agilis altas flamma percurrit trabes (vv. 642-644).

De igual modo, este "fogo de amor" conhece adjetivações alusivas ao que de poderoso (grauis) há na sua natureza (Quis me dolori reddit atque aestus graues/ reponit animo?, vv. 589-90) e ao seu caráter ímpio, nefando e irracional (impius, nefandus, insanus), em passos como Compesce amoris impii flammas (v. 165), Perge et nefandis uerte naturam ignibus (v. 173) ou Spes nulla tantum posse leniri malum/ finisque fammis nullus insanis erit (vv. 360361). Em segundo lugar, é comparado a uma loucura incontrolada (furor) que recebe, por sua vez, as qualificações de oculta, precipitada e impetuosa (cf. inclusus, praeceps y el poético proteruus): Torretur aestu tacito et inclusus quoque,/ quamuis tegatur, proditur uultu furor (vv. 362-63); Quid sinat inausum feminae praeceps furor? (v. 824); si tam proteruus incubat menti furor (v. 268). Em terceiro lugar, identifica-se com um crime horridum e nefandum (Stirpem perosa Solis uindicat Martis suil suasque, probris omne Phoebeum genus/ onerat nefandis, v. 126; expelle facinus mente castifica horridum, v. 169). Em quarto lugar, e para concluir, é equiparado a um mal, a uma doença de grandes dimensões (tantus, non leuis) e de caráter fatal (fatale): Spes nulla tantum possit leniri malum (v. 360); Minois defuncta leuil amore est, iungitur semper nefas (vv. 127-128); Quo tendis, anime? Quid furens saltus amas?/ Fatale miserae matris agnosco malum (vv. 112-113).

Nas referências às divindades do amor pode observar-se a incidência das adjetivações non castus e potens, com as quais significam, respetivamente, o desejo não casto de Fedra (pelo sintagma Venere non casta) e a omnipresença do deus (Cupido) como motor do seu furor: Resistet ille seque mulcendum dabit/ castosque ritus Venere non casta exuet? (vv. 236-237); Quid ratio possit? vicit ac regnat furor / potensque tota mente dominatur deus potens deus (vv. 184-185). 
Dos adjetivos referentes ao amor de Fedra sobressai de forma evidente, pelo seu significado, o termo fatalis. Com este termo, apenas usado por Fedra e uma só vez na tragédia em causa, intensifica-se a visão que do seu amor tem a rainha, como algo que não lhe coube escolher, antes que foi predestinado e motivado por forças sobre-humanas (o Fatum e a ação vingativa em concreto da deusa Vénus $\left.{ }^{16}\right)$; surge também integrado na série de amores da sua família (Stirpem perosa Solis inuisi Venus/ per nos catenas uindicat Martis suil suasque, probris omne Phoebeum genus/ onerat nefandis: nulla Minois leui/ defuncta amore est, iungitur semper nefas, vv. 124-128), em especial os amores da sua mãe (cf. miserae matris agnosco malum, v. 113; memorque matris metuere concubitus nouos, v. 170) ${ }^{17}$. E todos estes amores familiares são considerados tão monstruosos quanto a sua própria paixão, assim ocorrendo paralelismos entre a adjetivação do touro, objeto do amor de Pasífae (efferus, toruus, vv. 116-117) e as qualificações de Hipólito (efferatus, toruus, vv. 923, 416), etc. ${ }^{18}$

Fedra posiciona-se, portanto, não como um sujeito com liberdade para escolher os seus afetos, antes como uma vítima incapaz de combater o amor que the foi inculcado pelo Fatum, como um "objeto" estranho, portanto, às consequências nefandas desse mesmo amor. As valorações éticas (impius, nefandus, non castus) desse estado anímico tão poderoso e irracional, que lhe foi imposto de fora, residem, assim, sobretudo nas intervenções da Ama.

\section{Conclusões}

No momento de encerrar estas linhas gostaria de destacar as duas caracterizações básicas que podemos extrair do léxico adjetivo aplicado, essencialmente pela própria Fedra, ao seu comportamento e ao seu amor.

Quanto ao seu comportamento amoroso, ficou evidente um estado absoluto de "loucura" que, com tempo o dissemos, se verbaliza na afirmação mais dorida que faz a rainha de si mesma: quid ratio possit? Vicit ac regnat furor (v. 184). Acerca do seu amor, identificado com um furor que a lançou para o estado de loucura que comentámos, realça-se uma reafirmação desse

${ }^{16}$ Fedra descende, pelo lado materno, do Sol, raça odiada por Vénus. O Sol, com efeito, testemunhou as aventuras de Vénus com Marte e logo contou ao esposo de Vénus, Vulcano, que preparou um embuste ao convidar todos os deuses para verem juntos Vénus e Marte. Cf. J. Luque Moreno II 1980: 32, n. 62.

${ }^{17}$ Fedra era filha de Pasífae e de Minos. A sua mãe teve uma relação com um touro, da qual nasceu o Minotauro, monstro metade homem, metade touro. Cf. J. Luque Moreno II 1980: 31, n. 57. A projeção destes antecedentes na monstruosidade da paixão de Fedra vem também referida na quarta Heroide de Ovídio (vv. 53 sqq.).

${ }_{18}$ Alguns paralelismos reforçam a oposição mitológica entre os laços familiares de Fedra e Hipólito. São disso exemplo Pasífae/ Minos, vítimas de intensas paixões amorosas (para Fedra), e Antíope, uma amazona virgem (para Hipólito). Cf. J. Luque Moreno II 1980: 19. 
sentimento como malum fatale, ou seja, causado por uma força sobre-humana (o Fatum), externa à sua decisão.

Ambos os motivos, a "loucura" de Fedra e o caráter fatale, produto do furor, do seu amor, conduzem sem dúvida à neutralização da sua capacidade de escolha, da sua responsabilidade, assim se alcançando uma certa desculpa e uma postura de entendimento e compaixão para com a personagem, postura enquadrável nos efeitos da progressiva "reabilitação moral" que referimos no início deste trabalho, no essencial iniciada por Sófocles ${ }^{19}$.

${ }^{19}$ Comentei já acima a opinião de P. Grimal, segundo a qual terá sido Sófocles quem primeiro situou Teseu nos Infernos durante o desenlace da história e das intenções amorosas de Fedra para com Hipólito, esse lugar com fortes ressonâncias de "morte" - e a elas se agarra Fedra para pensar que, morto Teseu, nenhum pecado decorreria da sua união com Hipólito. Nas obras anteriores de Eurípides, Teseu é colocado na Tessália (Hipólito Velado), o que traz consigo a imoralidade chocante do duplo delito de incesto e adultério, situação que é no entanto suavizada em Hipólito portador da Coroa, com o motivo da ausência de Teseu devido a uma missão sagrada. Cf. J. Luque Moreno II 1980: 18. 